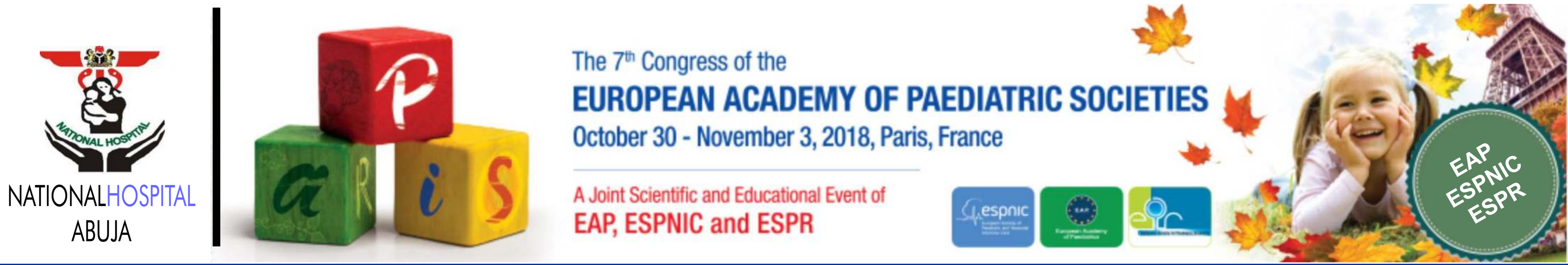

\title{
ESTIMATED GLOMERULAR FILTRATION RATE (eGFR) IN CHILDREN WITH HIVIAIDS
}

\section{Ezeh GO ${ }^{1}$, Oniyangi $\mathrm{O}^{1}$, Babaniyi IB ${ }^{1}$, Nwatah VE ${ }^{1 *}$, Eke FU ${ }^{2}$}

National Hospital Abuja, Nigeria, ${ }^{2}$ University of Port Harcourt Teaching Hospital, Nigeria

* Corresponding author: Nwatah VE; Department of Paediatrics,

National Hospital Abuja, Plot 132 Central Business District, Garki Abuja, Nigeria; nwatven@yahoo.com

\section{Introduction/Background}

Human Immunodeficiency Virus (HIV) is a retrovirus that could cause Acquired Immunodeficiency Syndrome (AIDS), a condition in humans in which the immune system fails, leading to life threatening opportunistic infections and direct organ damage ${ }^{1}$. HIV is associated with kidney disorders and this increases the risk of poor outcome in infected population. Kidney disease is more common in people of African descent in developed countries ${ }^{2}$. Chronic kidney disease is a common complication of HIV infection in this modern era of antiretroviral therapy (ART).

Estimation of GFR by Schwartz formula is a simple non-invasive means to assess kidney function. It has some advantages over other non-conventional ways of assessing GFR; and is relatively cheap, easy to calculate and non-invasive. Therefore, the use of the Schwartz formula to estimate GFR in asymptomatic HIV infected children is more likely to detect early stages of CKD than the use of serum creatinine alone ${ }^{17}$. We aim to estimate GFR by use of the SCHWARTZ formula in HIV infected children and to determine relationships (if any) between estimated GFR (eGFR) and age, and gender (sociodemographic variables) in HIV infected children seen at the National Hospital, Abuja.

\section{Methods and Materials}

The study was conducted at the National Hospital Abuja, a 220 bed tertiary hospital which is located in the Central Business District of the Abuja Municipal Area Council (AMAC). This was a prospective cross-sectional study of children with HIV infection who were consecutively enrolled. The study population comprised HIV infected children attending Paediatric Haematology Clinic, Out-patients' clinic and those admitted into the Paediatric wards, aged between 6 months and 15 years.

Data analysis was done using the Statistical Package for Social Sciences (SPSS) version 17. Descriptive statistics were used like simple proportions and frequency tables as well as Bar chart for age, gender, clinical staging and mean eGFR. The level of statistical significance was set at $p$ less than 0.05

\section{Results}

The age range of the study subjects was 12 months to 15 years with the mean \pm SD age of $8.21 \pm 3.61$ years. There were $129(58.4 \%)$ male and $92(41.6 \%)$ female children with male to female ratio $1: 0.7$ The mean \pm SD age for males was $7.87 \pm 3.49$ years while that for females was $8.70 \pm 3.71$ years. Thirty $(13.6 \%)$ children were underweight (weight less than $80 \%$ of expected weight for age, EWA) while $109(49.3 \%)$ had normal weight (weight of $80-100 \%$ of EWA). Sixty three $(28.5 \%)$ children were overweight $(>100-120 \% \mathrm{EWA}$ ) while $19(8.6 \%)$ were obese (weight $>120 \% \mathrm{EWA})$.

The estimated glomerular filtration rate (eGFR) for the study as determined by Schwartz formula had a range of 49.21 to $463.67 \mathrm{ml} / \mathrm{min} / 1.73 \mathrm{~m}^{2}$ with the mean $\pm \mathrm{SD}$ of $159.56 \pm 59.04 \mathrm{ml} / \mathrm{min}$. The severity of the clinical staging of the disease had no significant relationship with the occurrence of CKD as $p$ value $=0.295$.

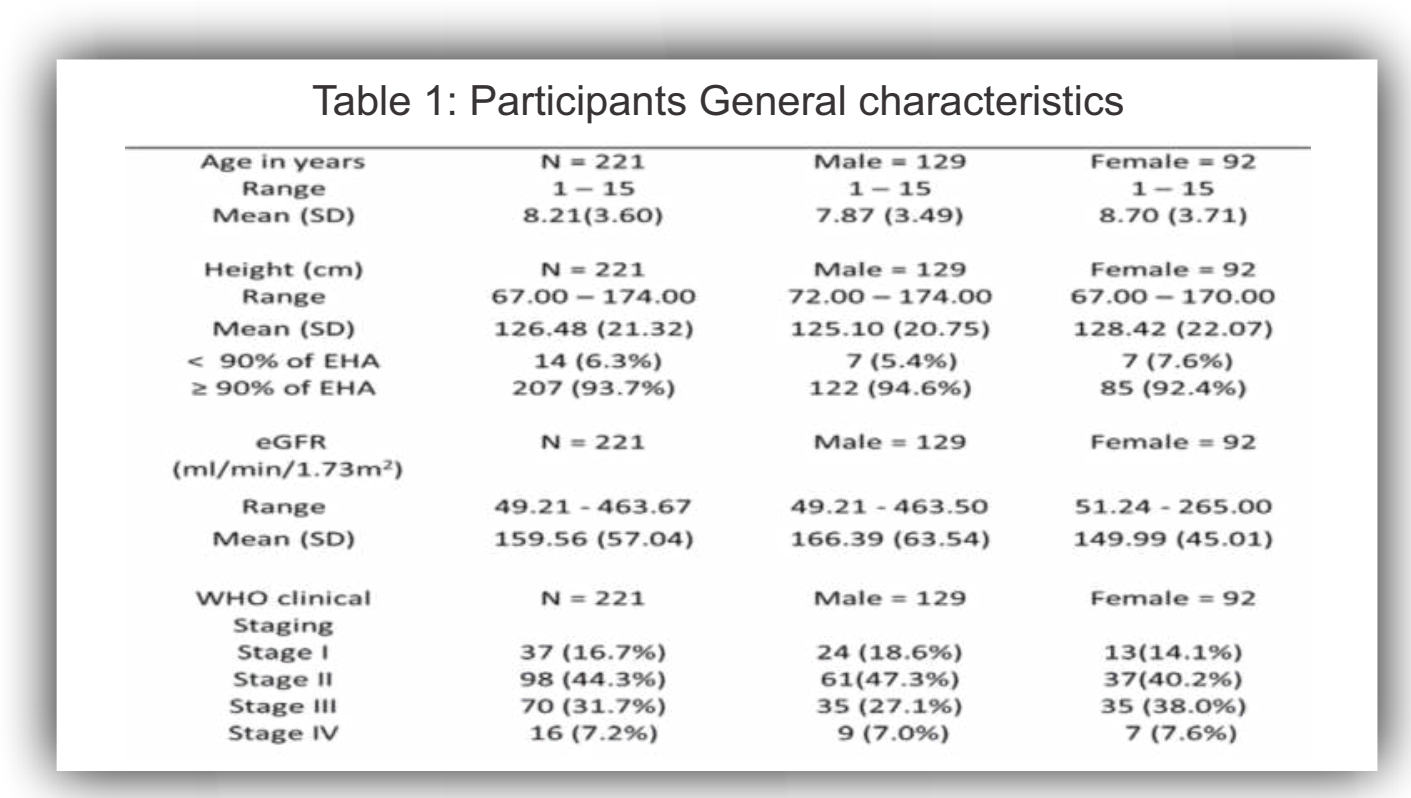

Table 2: Classification of eGFR as determined by Schwartz formula

\begin{tabular}{|c|c|c|c|c|c|}
\hline \multirow{2}{*}{\multicolumn{2}{|c|}{$\begin{array}{l}\text { eGFR ml/ } \mathrm{min} / \\
1.73 \mathrm{~m}^{2} \\
\text { Categories CKD } \\
\text { Stages }\end{array}$}} & \multicolumn{2}{|c|}{ Sex } & \multirow{2}{*}{$\mathrm{N}$ (\%) } & \multirow{2}{*}{$\begin{array}{l}\text { Mean eGFR } \pm \\
\text { SD }\end{array}$} \\
\hline & & Male & Female & & \\
\hline$\geq 90$ & 1 & 125 & 86 & $211(95.4)$ & $163.95 \pm 54.51$ \\
\hline $60-89$ & ॥ & 3 & 2 & $5(2.3)$ & $78.44 \pm 6.49$ \\
\hline $30-59$ & III & 1 & 4 & $5(2.3)$ & $55.29 \pm 4.50$ \\
\hline Total & & 129 & 92 & $221(100.0)$ & $159.56 \pm 59.04$ \\
\hline
\end{tabular}

Table 3 Intra Age - Group Gender Comparison of eGFR

\begin{tabular}{lcccc}
\hline Age in Years & $\begin{array}{c}\text { Mean } \pm \text { SD eGFR } \\
\text { Male }\end{array}$ & $\begin{array}{c}\mathbf{( m I} / \mathbf{m i n} / \mathbf{1 . 7 3 m ^ { 2 }} \\
\text { Female }\end{array}$ & t & Pvalue \\
\hline $1-3$ & $193.62 \pm 56.60$ & $101.03 \pm 38.34$ & 4.262 & 0.000 \\
$4-6$ & $165.64 \pm 77.43$ & $158.09 \pm 47.98$ & 0.376 & 0.708 \\
$7-9$ & $152.60 \pm 47.89$ & $149.57 \pm 39.12$ & 0.282 & 0.779 \\
$10-12$ & $155.42 \pm 53.79$ & $169.97 \pm 39.77$ & -1.048 & 0.300 \\
$13-15$ & $200.90 \pm 74.71$ & $141.66 \pm 43.09$ & 2.727 & 0.011 \\
\hline
\end{tabular}

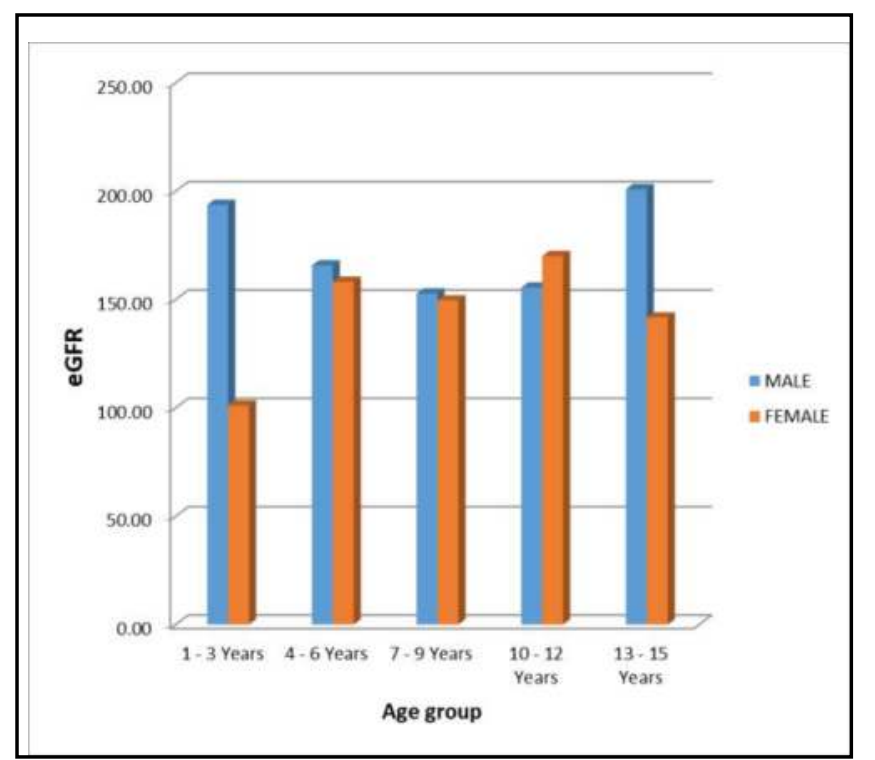

Figure 1: Bar chart showing age group and gender distribution of eGFR.

\section{Discussion}

The prevalence of chronic kidney disease (defined as eGFR of $<60 \mathrm{ml} / \mathrm{min} / 1.73 \mathrm{~m}^{2}$ ) in the study was $2.3 \%$ which is lower than figures previously reported from Nigeria by Iduoriyekenwen et al ${ }^{16}(5.1 \%$ and Abiodun et al ${ }^{10}(10.7 \%)$ both from Benin in 2013 and 2010 respectively, as well as Esezobar et al $(13.3 \%)$ from Lagos in 2010. Naiker et al ${ }^{20}$ in 2010 reviewed published literatures and reported prevalence of CKD in HIV infected patients of $3.5-4.7 \%$ in 31 European countries, Israel and Argentina, $1.1-5.6 \%$ in Brazil, $18 \%$ in Switzerland, $27 \%$ in India, $12.3 \%$ in Iran and $6-48.5 \%$ in SubSaharan Africa using different criteria for defining renal diseases in the various studies. The CKD prevalence from Nigeria of $5.1 \%$ was from serum creatinine (Scr) based study ${ }^{16}$ on HIV infected children on HAART while the $13.3 \%$ and $10 \%$ prevalence were from serum cystatin $\mathrm{C}$ based studies ${ }^{10}$ on HIV infected children yet to start antiretroviral drugs (ARVs).

Though not statistically significant the study revealed a trend of increasing eGFR with increasing age of the children except at the age group of $7-9$ years. The increase in eGFR with age had been noted in other studies ${ }^{28-30}$ where it was also found that at each age group males had higher eGFR than females. The eGFR was lower in males in the age group of $10-12$ years. This may be dependent on nephron damage, immunological compromise, viraemia or low CD4 + cell count in the age group.

In the study, there was no significant association between eGFR and clinical stages of HIV disease. The eGFR was found to be increasing with worsening clinical stage of the infection. There are similar reports from other studies that found that eGFR was independently associated with increased risk of HIV disease progression ${ }^{8,26,33}$. This may be connected to the different times acute insult occurred to the kidney, immunity of the individual, associated opportunistic infections and HIV viraemia.

The use of single measurement of glomerular filtration rate without repeating it in 3 or more months later to exclude transient reduction in glomerular filtration rate limits its relevance in the determination of CKD.

\section{Conclusion}

The study, in comparison with other studies, observed a lower prevalence of CKD in HIV infected children. Detection of CKD in HIV infection children may be more optimal if combined methods are employed.

Conflict of interest: None

Funding: None

Acknowledgement: We wish appreciate all the medical personnel who managed these children and also the patients as well as their parents / caregivers.

\section{References}

1. Suraj G. A Short Textbook of Paediatrics, 8th edn. Jaypee (Publ), New Delhi. 1998: 151 - 168

2. Fishman JA. BK virus nephropathy - polyomavirus adding insult to injury. N Engl J Med. 2002; 347:527-530.

3. Mocroft A, Kirk O, Reiss P, De Wit S, Sedlacek D, Beniowski M et al. (Eurosida group) Estimated glomerular filtration rate, chronic kidney disease and antiretroviral drug use in HIV positive patients. AIDS. 2010; 24:1667-1678.

4. NEW: kidney disease in HIV infected patients. HIV clinical resource Sept 2012. [serial on line] 2012 [assessed 2012 Apr 30]: [21 pages]. Available from: URL: http://www.hivguidelines.org/.../kidney-disease-in-hiv-infected-patients

5. HIV and AIDS Information: HIV and AIDS treatment in practice (HATiP). Kidney disease in people with HIV; a clinical review (part one). [serial on the internet] 2011 Jan [cited 2013 May 2]; [8 pages] Available from: URL: http://www.aidsmap.com/kidney-disease-in-people-with-HIV-aclinicalreview(partone)/page/1624034.

6. Choi Al, Rodriquez RA. Renal manifestation of Human immunodeficiency virus. HIV InSite Knowledge Base Chapter. [serial on the internet] 2003. [ updated 2008 Jan; assessed $2011 \mathrm{Ju}$ 30]; [20 screens]. Available from: URL: http://www.hininsite.ucsf.edu/InSite?page=kb-04-01-10

7. HIV and AIDS Information: HIV and AIDS treatment in practice (HATiP). Acute and Chronic Kidney Disease (part 2). [serial on the internet] $2011 \mathrm{Feb}$ [assessed 2013 Apr 20]; [18 pages]. Available from URL: http://www.aidsmap.com/Acute-and-Chronic-Kidney-disease/page/1633148/

8. Esezobor Cl, Iroha E, Oladipo O, Onifade E, Soriyan OO, Akinsulie AO et al. Kidney function of HIV infected children in Lagos, Nigeria: using Filler's serum cystatin $\mathrm{C}$ - based formula. J Int AIDS Soc. 2010; 13:17-25.

9. Wyatt CM, Shi Q, Novak JS, Brugwaho A, Hoover DR, Szczech L et al. Prevalence of kidney disease in HIV-infected and un-infected Rwandan women. PLoS ONE. 2011: 6:e18352-e18358.

10. Abiodun MT, Iduoriyekemwen NJ, Abiodun OP. Cystatin C based kidney function of HIV infected children in Benin City, Southern Nigeria. Int J Nephrol. 2012; 2012:1 -9 